2020-04

Nature contact, nature connectedness and associations with health, wellbeing and pro-environmental behaviours

\title{
Martin, L
}

http://hdl.handle.net/10026.1/15691

\subsection{6/j.jenvp.2020.101389 \\ Journal of Environmental Psychology \\ Elsevier BV}

All content in PEARL is protected by copyright law. Author manuscripts are made available in accordance with publisher policies. Please cite only the published version using the details provided on the item record or document. In the absence of an open licence (e.g. Creative Commons), permissions for further reuse of content should be sought from the publisher or author. 
Authors copy of Martin, L., White, M. P., Hunt, A., Richardson, M., Pahl, S., \& Burt, J. (2020). Nature contact, nature connectedness and associations with health, wellbeing and pro-environmental behaviours. Journal of Environmental Psychology, 68, 101389.

Nature contact, nature connectedness and associations with health, wellbeing and pro-environmental behaviours

Leanne Martin ${ }^{1,2}$, Mathew P. White ${ }^{3}$, Anne Hunt ${ }^{1}$, Miles Richardson ${ }^{4}$, Sabine Pahl$^{2}$ \& Jim Burt ${ }^{1}$

${ }^{1}$ Natural England

${ }^{2}$ School of Psychology, University of Plymouth, UK.

${ }^{3}$ European Centre for Environment and Human Health, University of Exeter Medical School, UK.

${ }^{4}$ Human Sciences Research Centre, University of Derby, UK.

Corresponding author: Leanne Martin, leanne.martin@plymouth.ac.uk

Declarations of interest: none 


\section{Abstract}

Contact with, and psychological connectedness to the natural world are both associated with various health and sustainability-related outcomes. To date, though, the evidence base has been fragmented. Using a representative sample of the adult population of England $(\mathrm{N}=4,960)$, we investigated the relationships between three types of nature contact, psychological connectedness, health, subjective wellbeing and pro-environmental behaviours within a single study. We found that specific types of nature contact, as well as individual differences in nature connectedness, were differentially associated with aspects of health, well-being and pro-environmental behaviours. Living in a greener neighbourhood was, unrelated to any wellbeing or sustainability outcomes. By contrast, visiting nature $\geq$ once a week was positively associated with general health and household pro-environmental behaviours. Moreover, people who watched/listened to nature documentaries reported higher levels of both pro-environmental behaviours. Nature connectedness was positively related to eudaimonic wellbeing and both types of pro-environmental behaviour. Connectedness moderated key relationships between nature contact, wellbeing and pro-environmental behaviours. The complexity of our findings suggests that interventions increasing both contact with, and connection, to nature, are likely to be needed in order to achieve synergistic improvements to human and planetary health. [191 words] 


\section{Highlights:}

- Visiting nature $\geq$ once/week was associated with better health.

- Nature connectedness was positively related to eudaimonic wellbeing.

- Nature connectedness was positively associated with pro-environmental behaviours.

- Nature documentaries were positively associated with pro-environmental behaviour

- Connectedness moderated relationships between nature contact and outcome variables 


\section{Introduction}

Public health and environmental sustainability present two of most significant global challenges of the 21st century (Horizon, 2020; WHO, 2015). With environmental degradation posing serious consequences to human health (WHO, 2013) and anthropogenic activity compromising environmental quality (United Nations, 2018), there is increasing recognition that these two challenges are inter-connected (Nisbet \& Gick, 2008; Graham \& White, 2016). As both public and planetary health under increasing pressure, researchers have called for a better integration of the sustainability and health/wellbeing research agendas (Depledge et al., 2019; Watts et al., 2015). One area of potential overlap concerns people's physical and psychological experiences of the natural world. There is growing evidence that contact with (non-threating) natural environments is associated with a range of positive health (Lovell, Depledge \& Maxwell, 2018; Twohig-Bennett \& Jones, 2018), well-being (Capaldi, Passmore, Nisbet, et al., 2015; McMahan \& Estes, 2015) and pro-environmental outcomes (Arendt \& Matthes; 2016; Hartig, Kaiser, \& Strumse, 2007; Weinstein et al., 2015). However, to date, these outcomes have been largely explored in parallel rather than simultaneously. Further, there is an increasing realisation that nature contact alone may be insufficient and that one also needs to feel psychologically connected to the nature world, i.e. to have positive emotional bonds with nature (Capaldi, Dopko \& Zelenski, 2014), for these potential benefits to accrue (Mackay \& Schmitt, 2019; Pritchard, Richardson, Sheffield \& McEwan, 2019; Whitburn, Linklater \& Abrahamse, 2019). 
Using data from a representative sample of the English adult population, the current research investigated the links between three different types of nature contact and both self-reported health/well-being outcomes and pro-environmental behaviours within the same study. We also examined the role nature connectedness might play in any such relationships. Previous experimental research found that greater nature contact led to better outcomes via improved psychological connectedness, at least partially (Mayer, Frantz, Bruehlman-Senecal \& Dolliver, 2009). As our data were cross-sectional rather than experimental, and our measure of nature connectedness was a trait measure, we focused on moderation rather than mediation. We hypothesised that the level of existing (trait) nature connectedness would affect how nature contact experiences would relate to both health / wellbeing and pro-environmental outcomes.

\subsection{Nature Contact}

Nature contact refers to any human interaction with a biophysical system, including flora, fauna, and geological landforms (Zylstra et al., 2014; Hartig et al., 2014). There is growing evidence that people are spending less time outside and more time indoors (Office for National Statistics, 2017) which in turn leads to less direct contact with the natural world (Soga \& Gaston, 2016). In the UK for instance, people spend considerably more recreational time in front of TV and computer screens and listening to the radio and music (around 15hrs per week in the UK), than they do engaged in outdoor activities (around 2hrs per week in the UK; ONS, 2017), which in turn may reduce any benefits to health and well-being that might derive from outdoor nature-based contact (Cox et al., 2017; Markevych et al., 2017). 
However, time outdoors is not the only way nature contact can be established. Keniger et al. (2013), for instance, distinguished between incidental (e.g. neighbourhood greenspace exposure), intentional (e.g. visits to natural spaces), and indirect (e.g. television programmes) contact. Although there is fairly consistent evidence of positive relationships between: a) living in neighbourhoods with more natural features (incidental contact) and a range of health and wellbeing benefits (Dadvand et al., 2016; Gascon et al., 2017, van den Bosch \& Sang, 2017), and b) spending recreational time in nature and positive health and wellbeing (Shanahan, et al., 2016; White et al., 2019), the relationships between nature contact and proenvironmental behaviour are far less established.

While there has been some research into indirect contact via indoor plants (Bringslimark, Hartig, \& Patil, 2009), home views (Grinde \& Patil, 2009; Nutsford et al., 2016) and virtual reality nature (Tanja-Dijkstra et al. 2018; White et al., 2018), and health and wellbeing outcomes, there has been relatively little work exploring the links to indirect contact in the form of nature-based TV and radio programmes. Given the amount of screen-time we now engage in (ONS, 2017), this is perhaps surprising, and we note that the two studies that we are aware of (Arendt \& Matthes, 2016; Zelenski, Dopko \& Capaldi, 2015) both focus on pro-environmental behavioural outcomes rather than health and wellbeing. Moreover, high profile nature series such as the BBC's Blue Planet 2 are credited in the media with transforming political and societal attitudes to the natural world and the anthropogenic threats it is facing (Rawlinson, 2017), and thus a lack of supporting evidence is particularly surprising.

By including the three types of contact in the same study, indeed in the same statistical analyses, we were able to explore the relative predictive effects of 
incidental (neighbourhood greenness), direct (likelihood of visiting nature for recreation at least once a week) and indirect (watching/listening to nature programmes on the TV/Radio) contact for both health and wellbeing outcomes and a range of self-reported pro-environmental behaviours for the first time.

\subsection{Nature Connectedness}

Nature connectedness refers to an individual's subjective sense of their relationship with the natural world and has been operationalised in a variety of ways (Martin \& Czellar, 2016). These include the Inclusion of Nature in Self Scale (Schulz, 2001), the Connectedness to Nature Scale (CNS, Mayer \& Frantz, 2004) and the Nature Relatedness Scale (Nisbett, Zelensky \& Murphy, 2009) and it is recognised as having strong links to related concepts such as Environmental Identity (Clayton, 2003). Although the various measures are related, some focus more on emotional connectedness, while others reflect more cognitive processes and appraisals (Tam, 2013).

Recent meta-analyses indicate that higher levels of nature connectedness (broadly defined) are positively associated with both higher levels of evaluative and eudaimonic wellbeing (Capaldi, Dopko \& Zelenski, 2014; Pritchard, Richardson, Sheffield \& McEwan, 2019) and also more pro-environmental behaviours (Mackay \& Schmitt, 2019; Whitburn, Linklater \& Abrahamse, 2019). Whilst making important contributions, the studies included within such analyses predominantly use relatively small $(\mathrm{N}<400)$, non-representative samples which are unable to adequately control for socio-demographic covariates that have previously been shown to be important for both health, well-being and pro-environmental behaviours, including area-level deprivation and socio-economic status (Alcock et al., 2017; Meyer, Castro-Schilo \& 
Aguilar-Gaxiola, 2014). It is unclear, therefore, both how generalisable these associations are beyond the specific samples used, and how important the relationships between nature connectedness and these outcomes are in comparison to long-established socio-demographic factors. This type of comparison helps policy makers understand concepts such as nature connectedness by showing not only that any relationships with key policy outcomes such as health and well-being are demonstrable at the population level, but also by showing that we can explain outcomes over and above already well established and understood sociodemographic predictors (Hunt et al., 2017).

\subsection{Interplay between contact and connection}

With moderate positive associations observed between nature contact and nature connectedness (Mayer and Frantz, 2004; Nisbet, Zelenski \& Murphy, 2009), it has been suggested that the two constructs may operate inter-dependently (Gifford, 2014). Prior theory and research has typically considered nature connectedness to mediate the relationships between nature contact and positive outcomes, i.e. more contact increases feelings of connectedness, which in turn leads to positive outcomes (Mayer et al., 2009). Experimental studies have supported this by demonstrating that increased contact with natural environments, heightens state nature connectedness (i.e. connectedness in the moment), which in turn increases wellbeing (Mayer, et al. 2009) and pro-environmental behaviours (Whitburn, Linklater \& Milfont, 2018). Although less well-researched, the reverse direction of causality is also possible. Greater nature connectedness may lead to people seeking out more nature contact by, for instance, buying a home in a greener area, visiting nature more often, or being more willing to watch nature programmes on TV. 
Due to the cross-sectional nature of the current data we were unable to test either direction of causality, since contact, connectedness and outcomes were all obtained during the same in-home interview. Nevertheless, given that our measure of nature connectedness is effectively a trait measure that is fairly stable over time, we were able to explore a different, and potentially equally important, moderation relationship. Specifically, are the relationships between nature contact (using our three different types) and outcomes (health, wellbeing and pro-environmental behaviours) different for people with different levels of nature connectedness?

We are aware of just two small scale studies that have previously examined this possibility. The first found that nature-related leisure activities predicted greater endorsement of pro-environmental attitudes, but only for individuals with a high trait emotional connection to nature (Ojala, 2009). Similarly, Arendt \& Matthes (2016) found that watching a nature documentary increased donations to environmental organisations, but only for participants who were already highly connected to nature. Taken together, these findings suggest that, for pro-environmental behaviours at least, contact with nature may promote the most beneficial outcomes among individuals who are already highly connected with it. As far as we are aware, no previous research has examined whether trait connectedness moderates the associations between nature contact and health/wellbeing outcomes.

Thus, a further aim of the current research was to examine the interplay of nature contact and nature connectedness. We extended previous work by testing potential of nature connectedness to moderate the link between nature contact and proenvironmental behaviour among a large nationally representative sample. We also investigated whether nature connectedness moderated the link between nature contact and health/wellbeing for the first time. 


\subsection{The Current Research}

We focused on two key questions: how are a range of health, wellbeing and proenvironmental outcomes related to different types of nature contact; and does the psychological construct of (trait) nature connectedness moderate these associations? The research extended previous work in the following ways:

1) We investigated the relations between nature contact and a range of health, wellbeing and pro-environmental outcomes in the same study, thus bridging the traditional gap between these two lines of research.

2) Nature contact was operationalised in three different ways: incidental, intentional and indirect. This helps us understand the relative roles of different types of nature contact.

3) We accounted for a wide range of individual and area-level covariates that are known to be important for our key outcomes. This practice gives us greater confidence that nature factors rather than other underlying factors drive the findings.

4) We assessed the magnitude of the effects of nature contact and trait connectedness on our outcome variables, by comparing their effect sizes to those of selected key socio-demographics. Using such benchmarks connects our findings to other disciplines and helps researchers and policymakers assess their relative importance.

5) Overall, this research extends previous theoretical and conceptual perspectives describing nature benefits on health (Hartig et al., 2014) towards the concept of planetary health (Whitmee et al., 2015). 


\section{Method}

\subsection{MENE Survey Overview}

The Monitor of Engagement with the Natural Environment (MENE) survey is commissioned by Natural England, a part of DEFRA's social science research programme. It is part of a face-to-face in-home omnibus survey conducted by trained interviewers using computer-assisted personal interviewing (Natural England, 2018). Data are collected across the whole of England, and throughout the year, in order to reduce potential geographical and seasonal biases (Natural England, 2018). As part of the United Kingdom's official statistics, substantial effort is made to ensure sampling is as representative of the adult English population as possible. Key features include: 1) a computerised sampling system which integrates the Post Office Address with the 2001 Census small area data at output area level to produce replicated waves of multi-stage stratified samples; 2) areas within each Standard Region are stratified into population density bands and within band, in descending order by percentage of the population in socio-economic Grade I and II and 3) quotas set by sex, presence of children and working status to ensure a balanced sample of adults (Natural England, 2018).

\subsection{Participants}

Participants were drawn from eight waves of the MENE survey that contained the Nature Connection Index (NCI, Hunt et al., 2017). Data were collected on a quarterly basis between May 2015- February 2018, during the months of May, August, November and February. The sample comprised of a total 4,960 adults (2,550 females) aged between 16 and 95 years. 


\subsection{Measures}

\subsubsection{Outcome Variables}

Health \& Wellbeing

General health was measured using a single item 'How is your health in general?' (1, 'Very Bad' - 5, 'Very Good'), $M=3.90, S D=.92$. Five respondents who selected 'don't know' were excluded from analyses using this indicator, resulting in a reduced sample of 4,955 for general health models. Wellbeing items were developed by the UK's Office of National Statistics (ONS, 2011): 1) 'Overall how satisfied are you with life nowadays?' (Evaluative wellbeing) and 2) 'Overall to what extent do you feel that the things you do in your life are worthwhile?' (Eudaimonic wellbeing). Both items are scored on an 11-point Likert scale (0, 'Not at all' - 10, 'Completely'), with higher scores indicating better wellbeing. Mean evaluative and eudaimonic wellbeing in the present study were $7.52(S D=1.95)$ and $7.73(S D=1.88)$, respectively. Despite evident positive skews for both wellbeing outcomes, multivariate analysis was considered appropriate given the large sample size (Lumley et al., 2002). Sensitivity analyses conducted on binary wellbeing outcomes (high vs. low), yielded largely consistent findings, indicating that the distributions were not affecting the reliability of our results (Supplementary Material 1a \& 1b).

\section{Pro-environmental Behaviours}

Respondents were required to indicate which environment-related activities they had undertaken during the previous 12 months. Each of the items were binary coded to represent engagement in that specific behaviour and the items were subjected to a principal components analysis with an orthogonal varimax rotation $\left(K M O=.75 ;\right.$ Bartlett's test of sphericity, $\left.\chi^{2}(36)=5339 ., p=.000\right)$. The model yielded 
a two-factor solution, with Factor 1 and Factor 2 accounting for $28.09 \%$ and $14.95 \%$ of the variance, respectively (Table 1). 


\begin{tabular}{lcc}
\hline & $\begin{array}{c}\text { Factor 1 } \\
\text { Household } \\
\text { Behaviours }\end{array}$ & $\begin{array}{c}\text { Factor 2 } \\
\text { Nature } \\
\text { conservation } \\
\text { behaviours }\end{array}$ \\
\hline I usually recycle items rather than throw them away & .60 & -.07 \\
I usually buy eco-friendly products and brands & .65 & .20 \\
I usually buy seasonal or locally grown food & .68 & .10 \\
I choose to walk or cycle instead of using my car when I can & .57 & .04 \\
I encourage other people to protect the environment; & .60 & .30 \\
I am a member of an environmental or conservation & .14 & .68 \\
organisation & & .66 \\
I volunteer to help care for the environment; & .07 & .61 \\
I donate money at least once every three months to support & .18 & .70 \\
an environmental or conservation organisation & -.03 & \\
I donate my time at least once every three months to an & & \\
environmental or conservation organisation & & \\
\hline
\end{tabular}

These factors formed the basis of our two pro-environmental behaviour indicators which we labelled: 'household' and 'nature conservation' pro-environmental behaviours, respectively. Although we recognise that these two factors have similarities to the distinction between private and public spheres (Stern, 2000), they are not identical and we wanted to highlight the fact that the second dimension is focused on conservation issues in particular (as opposed to other environmental topics e.g. transport/energy etc.). The number of behaviours reported for each factor were totalled to yield scores of $0-5$ for household behaviours $(M=2.07, S D=1.44)$ and $0-4$ for nature conservation behaviours $(M=.23, S D=.62)$ with higher scores on each item indicating a greater propensity to act sustainably.

\subsubsection{Predictor Variables}

Nature Contact

Following previous research (e.g. Weinstein et al., 2015), a range of nature contact metrics were operationalised. 
Incidental contact (neighbourhood greenspace) was determined using information about the Lower-layer Super Output Area (LSOAs) in which respondents lived. LSOAs are produced by the Office for National Statistics and represent discrete geographic areas of similar population size. There are 32,484 LSOAs in England (2011 census), each containing approximately 1,500 residents. This information was added by the authors to the MENE dataset. The percentage of land cover incorporating public greenspace and domestic gardens within each LSOA (at the resolution of $10 \mathrm{~m}^{2}$ ) was derived from the Generalised Land Use Database (Office of the Deputy Prime Minister, 2005). As this data was only available for 4,875 participants, analyses including this variable exclude 85 participants. The mean proportion of neighbourhood greenspace within the current study was $64.38 \%$ ( $S D=$ 18.70).

Intentional contact (nature visits) was based on a single item assessing respondents' average visit frequency over the last twelve months ('More than once per day', 'Every day', 'Several times a week', 'Once a week', 'Once or twice a month', 'Once every 2-3 months', 'Once or twice', 'Never'; Natural England, 2018). To enable comparability across studies (e.g. Shanahan et al., 2016), the item was dichotomised according to whether respondents visited natural spaces at least once a week ( $v s$. less than weekly $=$ reference).

Indirect contact (Nature programmes TV/radio) was operationalised according to whether respondents reported 'watching or listening to nature programmes on the TV or radio, either regularly or occasionally' (Yes vs. No = reference). This item was included as a relatively novel measure of contact, which may have relevance when considering policy and practice implications for people with limited access to natural places. 
Nature Connectedness

The Nature Connection Index (NCI, Hunt et al, 2017) was developed by Natural England, as a concise measure of nature connectedness suitable for use within a nationally representative UK based survey. The $\mathrm{NCI}$ has favourable psychometric properties, with good levels of internal reliability $(\alpha=.92$ in the current study) and convergent validity with US developed scales such as the Nature Relatedness Scale and the Inclusion of Nature in the Self measure (Richardson et al., 2019). The scale consists of six items scored on a 7-point Likert scale (1, “Completely disagree" - 7, “Completely agree") pertaining to an individual's trait sense of their general emotional relationship with the natural world (e.g. 'I feel part of nature'). Items are scored according to a weighted points index (Hunt et al., 2017) resulting in scores from 0 to 100 , with higher scores indicating a stronger sense of connection $(M=60.12, S D=28.27)$.

\subsubsection{Control Variables}

Given that our outcome and predictor variables have previously been shown to be associated with a range of covariates (e.g. socio-economic status, Meyer, Castro-Schilo \& Aguilar-Gaxiola, 2014; neighbourhood deprivation, Jokela et al., 2015) control variables were created using available data from the MENE survey, as well as additional LSOA datasets and included within the multivariate analyses.

Area-level control variables

Respondent LSOA codes were used to derive area-level urbanicity and deprivation indicators. Urbanicity was categorised as: rural (hamlet/village/town- 
fringe) vs. urban (= reference) and included $14 \%$ and $86 \%$ of the sample, respectively. Quintiles of the Index of Multiple Deprivation (IMD) scores were also calculated, ranging from the lowest level of deprivation $(M=7.00, S D=2.47=$ reference) to the highest $(M=50.20, S D=9.30)$.

Individual-level control variables

Demographic controls included: gender (female, male = reference); age (1634 = reference, 35-64, 65+); ethnicity (White British, vs. Other = reference); working status (unemployed $=$ reference, full-time employed, part-time employed, in education, retired); marital status (married/cohabiting, single/widowed/divorced= reference); household composition (living alone = reference, with adults, with children, with adults and children); and socio-economic group based on occupation (AB (highest), C1, C2, DE (lowest) = reference). The year in which respondents completed the MENE survey was also included as a covariate $(2015 / 16=$ reference, 2017/18).

Related outcome control variables

With moderate positive correlations between outcome variables (Table 2), we controlled for related outcome variables within the multivariate models, to better understand the unique contributions of predictor variables on each outcome variable separately. Specifically, the health and wellbeing models controlled for other components of health/wellbeing, whereas the pro-environmental models controlled for the remaining pro-environmental behaviour.

\subsection{Analytical Approach}


An initial series of linear regression models were fitted to examine the relative contributions of different types of nature contact and nature connectedness to the domains of health / well-being and pro-environmental behaviors. To assess the magnitude of the effects of nature contact and connection on the outcome variables, where appropriate, we compared the effects of a change in the predictor variable on the unstandardised coefficients for each outcome measure, to those of relevant control variables. For continuous variables (greenspace and nature connectedness) unstandardised coefficients relate to the change in scores on the outcome measure for a $1 \%$ increase in the predictor variable. A useful way of interpreting this relationship is to consider the effect of a more substantial change, thus following White et al., (2013) we compared the difference in scores on outcome measures, between greenspace/nature connectedness scores of 1 standard deviation below the mean, to those of scores of 1 standard deviation above the mean. Prior research suggests that females (vs. males) and individuals from higher (vs. lower) socioeconomic groups, on average, report better wellbeing (Cummins, Eckersley, Pallant, Van Vugt \& Misajon, 2003; Rout, 1999) and increased pro-environmental behaviours (Scannell \& Gifford, 2013). Accordingly, gender (female vs. male) and belonging to socio-economic group $\mathrm{AB}$ (highest vs. DE, lowest) were selected as comparator variables.

A second series of linear regression models were specified to examine whether trait nature connectedness moderated the associations between nature contact and the five outcome variables. Models presented in the main text are adjusted for individual and area-level control variables, plus related outcome controls. Unadjusted and partially-adjusted models (accounting for individual and area-level covariates, but not related outcomes) are reported in Supplementary 
Materials $2 \mathrm{a}-5 \mathrm{~b}$. The direction of the associations between variables were largely consistent with those observed in final models.

\section{Results}

\subsection{Descriptive Data}

Increased contact with, and connection to, nature were generally associated with more favourable outcomes across health, wellbeing and sustainability domains, with three exceptions: no significant correlation was found between a) greenspace and general health and b) nature programmes and evaluative wellbeing; and c) nature programmes and general health had a small negative correlation (Table 2).

\subsubsection{Main Findings: Initial models}

A summary of the main results of the fully adjusted linear regression models are presented in Table $3 \mathrm{a}$ and $3 \mathrm{~b}$ (full models including control variables are reported Supplementary Tables S6a-S7b). All variance inflation factors (VIF) for the models were $<3.83$, indicating that multicollinearity was not an issue (as confirmed by the low correlations between exposure metrics in Table 2).

Incidental contact: the only outcome significantly related to neighbourhood greenspace was general health. Living in a greener neighbourhood was associated with worse health $(b=-.0021, p=.008)$.

Intentional contact: visiting nature $\geq$ once a week ( $v s$. < once a week) was positively related to general health $(b=.2002, p<.001)$ and household pro-environmnetal behaviours $(b=.3412, p<.001)$. 
Table 2: Bivariate relationships between nature contact, nature connectedness and outcome variables.

$$
1
$$

3

5

6

7

8

1. Neighbourhood greenspace

2. Nature visits ( $\geq$ once a week)

3. Nature progs. TV/radio (yes)

4. Nature Connectedness

5. General Health

6. Evaluative wellbeing

7. Eudaimonic wellbeing

8. Household PEB

9. Nature conservation PEB

\section{$64.38(18.70)$}

$.10^{\star \star \star} \quad \mathrm{N}=2954$ (59.56\%)

$.10^{\star * *}$

$.04^{\star *}$

$-.01$

$.06^{\star * *}$

$.06^{* * *}$

$.12^{* * *}$

$.07^{\star \star *}$

$\mathrm{N}=2954$ (59.56\%)

$.12^{\star \star \star}$

$.18^{* * *}$

$.22^{\star * *}$

\section{$\mathrm{N}=2503(50.46 \%)$}

$.21^{* * *}$

$60.12(28.27)$

$-.03^{*}$

.02

$.05^{\text {** }}$

3.90 (.92)

$.12^{\star \star \star}$

$.34^{\star \star \star}$

7.52 (1.95)

$.06^{\star * *}$

$.22^{\star \star \star}$

$.29^{\star \star *}$

$.66^{\star * *}$

$.34^{\star * *}$

$.11^{\star *}$

$.06^{* * *}$

$7.73(1.88)$

$18^{* * *}$

$.19^{* * *}$

$.03^{*}$

$.03^{*}$

$.12^{\star \star \star}$

2.07 (1.44)

$.06^{* * *} \quad .31^{* * *}$

$.23(.62)$

Note: ${ }^{* *} p<0.001 ;{ }^{* *} p<0.01 ;{ }^{*} p<0.05$. PEB $=$ Pro-environmental behaviours. Figures below the diagonal derived from Pearson coefficients for continuous data and point bi-serial correlations for binary variables. Figures in bold along the diagonal express the Mean (Standard Deviation) of continuous variables and Numbers (\%) for binary variables. 
Indirect contact: intriguingly, watching/listening to nature programmes was marginally associated with poorer evaluative wellbeing $(b=-.0860, p=.045)$ but higher levels of both types of pro- environmental behaviour (household behaviours $b=.6779, p<$ .001 ; conservation behaviours $b=.0706, p<.001$ ).

Nature connectedness: nature connectedness was positively related to eudaimonic wellbeing $(b=.0089, p<.001)$, household pro-environmental behaviours $(b=.0110$, $p<.001)$ and nature conservation behaviours $(b=.0020, p<.001)$.

\subsubsection{Comparisons to socio-demographic comparators.}

Estimated marginal means for outcome variables as a function of environmental indicators and selected socio-demographic comparators (gender: female vs. male; social grade: $A B$ vs. $D E$ ) are presented in Table 4. Visiting nature at least once a week (vs. less than weekly) was associated with an increase in general health (5.15\%) nearly twice as large as the increase associated with having a high vs. low socio-economic status (3.08\%). For eudaimonic wellbeing, the increase associated with a nature connectedness score 1 standard deviation above vs. 1 standard deviation below the mean (6.59\%) was substantially larger than the increase associated with being female $v s$. male $(1.03 \%)$ or having higher vs. lower socioeconomic status (1.68\%).

The increase in household behaviours associated with visiting nature $\geq$ once a week $(17.11 \%)$, watching/listening to nature programmes (32.85\%) and having a 
Table 3a: Summary of fully-adjusted linear regression models predicting health and wellbeing outcomes, after controlling for individual, area-level and related outcome covariates.

\begin{tabular}{|c|c|c|c|c|c|c|c|c|c|c|c|c|}
\hline & \multicolumn{4}{|c|}{ General Health } & \multicolumn{4}{|c|}{$\begin{array}{l}\text { Evaluative Wellbeing } \\
\text { (life satisfaction) }\end{array}$} & \multicolumn{4}{|c|}{$\begin{array}{l}\text { Eudaimonic Wellbeing } \\
\text { (worthwhile activities) }\end{array}$} \\
\hline & $\boldsymbol{b}$ & $95 \% \mathrm{Cl} \mathrm{b}$ & $\beta$ & $p$ & $\boldsymbol{b}$ & $95 \% \mathrm{Cl} \mathrm{b}$ & $\beta$ & $p$ & $b$ & $95 \% \mathrm{Cl} b$ & $\beta$ & $p$ \\
\hline \multicolumn{13}{|l|}{ Initial Models } \\
\hline $\begin{array}{l}\text { Neighbourhood greenspace (\%) } \\
\text { Nature visits ( } \geq \text { once a week) }\end{array}$ & $\begin{array}{l}-.0021 \\
.2002\end{array}$ & $\begin{array}{c}(-.0037,-.0006) \\
(.1526, .2477)\end{array}$ & $\begin{array}{r}-.0431 \\
.1066\end{array}$ & $\begin{array}{r}.008 \\
<.001\end{array}$ & $\begin{array}{l}.0016 \\
.0513\end{array}$ & $\begin{array}{l}(-.0012, .0044) \\
(-.0342, .1368)\end{array}$ & $\begin{array}{l}.0151 \\
.0129\end{array}$ & $\begin{array}{l}.268 \\
.240\end{array}$ & $\begin{array}{l}.0006 \\
.0682\end{array}$ & $\begin{array}{l}(-.0021, .0033) \\
(-.0144, .1508)\end{array}$ & $\begin{array}{l}.0063 \\
.0179\end{array}$ & $\begin{array}{l}.644 \\
.106\end{array}$ \\
\hline Nature progs. TV/radio (Yes) & -.0097 & $(-.0567, .0373)$ & -.0053 & .685 & -.0860 & $(-.1699,-.0021)$ & -.0220 & .045 & .0677 & $(-.0133, .1488)$ & .0181 & .102 \\
\hline Nature connectedness (\%) & .0001 & $(-.0007, .0009)$ & .0045 & .736 & -.0015 & $(-.0030, .0000)$ & -.0214 & .055 & .0089 & $(.0075, .0104)$ & .1348 &.$<.001$ \\
\hline $\begin{array}{l}\text { Constant } \\
\mathrm{N} \\
\text { Adjusted } \mathrm{R}^{2}\end{array}$ & $\begin{array}{l}2.9354 \\
4869 \\
.26\end{array}$ & $(2.7417,3.1291)$ & - & $<.001$ & $\begin{array}{l}.9466 \\
4869 \\
.47\end{array}$ & $(.5713,1.3219)$ & - & $<.001$ & $\begin{array}{l}1.7883 \\
4869 \\
.47\end{array}$ & $(1.4285,2.1482)$ & - & $<.001$ \\
\hline \multicolumn{13}{|l|}{ Moderation Models } \\
\hline $\begin{array}{l}\text { Neighbourhood greenspace (\%) } \\
\text { Nature visits ( } \geq \text { once a week) } \\
\text { Nature progs. TV/radio (Yes) } \\
\text { Nature connectedness (\%, NC) }\end{array}$ & $\begin{array}{l}-.0032 \\
.1923 \\
-.0488 \\
-.0013\end{array}$ & $\begin{array}{c}(-.0062,-.0001) \\
(.0851, .2995) \\
(-.1575, .0599) \\
(-.0043, .0016)\end{array}$ & $\begin{array}{l}-.0644 \\
.1024 \\
-.0265 \\
-.0411\end{array}$ & $\begin{array}{r}.040 \\
<.001 \\
.379 \\
.374\end{array}$ & $\begin{array}{l}.0003 \\
-.0687 \\
.2014 \\
-.0019\end{array}$ & $\begin{array}{r}(-.0051, .0057) \\
(-.2602, .1229) \\
(.0074, .3954) \\
(-.0071, .0034)\end{array}$ & $\begin{array}{l}.0024 \\
-.0173 \\
.0516 \\
-.0270\end{array}$ & $\begin{array}{l}.926 \\
.482 \\
.042 \\
.926\end{array}$ & $\begin{array}{l}.0040 \\
.2373 \\
-.2101 \\
.0120\end{array}$ & $\begin{array}{l}(-.0012, .0092) \\
(.0525, .4221) \\
(-.3974,-.0228) \\
(.0069, .0171)\end{array}$ & $\begin{array}{l}.0396 \\
.0621 \\
-.0561 \\
.1811\end{array}$ & $\begin{array}{l}.135 \\
.012 \\
.028 \\
<.001\end{array}$ \\
\hline $\begin{array}{l}\text { Greenspace } \times \text { NC } \\
\text { Visits } \times \text { NC } \\
\text { Nature progs. } \times \text { NC }\end{array}$ & $\begin{array}{l}.0000 \\
.0001 \\
.0006\end{array}$ & $\begin{array}{l}(-.0000, .0001) \\
(-.0015, .0018) \\
(-.0010, .0023)\end{array}$ & $\begin{array}{l}.0419 \\
.0057 \\
.0265\end{array}$ & $\begin{array}{l}.432 \\
.866 \\
.440\end{array}$ & $\begin{array}{l}.0000 \\
-.0020 \\
-.0048\end{array}$ & $\begin{array}{l}(-.0001, .0001) \\
(-.0009, .0049) \\
(-.0077,-.0019)\end{array}$ & $\begin{array}{l}.0270 \\
.0387 \\
-.0932\end{array}$ & $\begin{array}{l}.548 \\
.171 \\
.001\end{array}$ & $\begin{array}{l}-.0001 \\
-.0029 \\
.0046\end{array}$ & $\begin{array}{l}(-.0001, .0000) \\
(-.0057,-.0001) \\
(.0018,0074)\end{array}$ & $\begin{array}{l}-.0685 \\
-.0573 \\
.0940\end{array}$ & $\begin{array}{l}.130 \\
.044 \\
.049\end{array}$ \\
\hline $\begin{array}{l}\text { Constant } \\
\mathrm{N} \\
\text { Adjusted } \mathrm{R}^{2} \\
\text { Delta } \mathrm{R}^{2} \\
\end{array}$ & $\begin{array}{l}3.0239 \\
4869 \\
.26 \\
.00 \\
\end{array}$ & $(2.7684,3.2794)$ & - & $<.001$ & $\begin{array}{l}.9478 \\
4869 \\
.47 \\
.00 \\
\end{array}$ & $(.4779,1.4277)$ & - & $<.001$ & $\begin{array}{l}1.6213 \\
4869 \\
.47 \\
.00 \\
\end{array}$ & $(1.1595,2.0830)$ & - & $<.001$ \\
\hline
\end{tabular}


Table 3b: Summary of fully adjusted linear regression models predicting pro-environmental behaviours (PEB), after controlling for individual, area-level and related outcome covariates.

\begin{tabular}{|c|c|c|c|c|c|c|c|c|}
\hline & \multicolumn{4}{|c|}{ Household PEB } & \multicolumn{4}{|c|}{ Nature Conservation PEB } \\
\hline & $\boldsymbol{b}$ & $95 \%$ Cl b & $\beta$ & $p$ & $\boldsymbol{b}$ & $95 \% \mathrm{Cl} b$ & $\beta$ & $p$ \\
\hline \multicolumn{9}{|l|}{ Initial Models } \\
\hline $\begin{array}{l}\text { Neighbourhood greenspace (\%) } \\
\text { Nature visits ( } \geq \text { once a week) }\end{array}$ & $\begin{array}{l}.0012 \\
.3412\end{array}$ & $\begin{array}{r}(-.0012, .0036) \\
(.2689, .4136)\end{array}$ & $\begin{array}{l}.0157 \\
.1164\end{array}$ & $\begin{array}{r}.320 \\
<.001\end{array}$ & $\begin{array}{l}-.0008 \\
.0148\end{array}$ & $\begin{array}{l}(-.0020, .0003) \\
(-.0205, .0501)\end{array}$ & $\begin{array}{l}-.0243 \\
.0116\end{array}$ & $\begin{array}{l}.165 \\
.411\end{array}$ \\
\hline Nature progs. TV/radio (Yes) & .6779 & $(.6057, .7501)$ & .2356 & $<.001$ & .0706 & $(.0345, .1067)$ & .0563 & $<.001$ \\
\hline Nature connectedness (\%) & .0110 & $(.0097, .0123)$ & .2158 & $<.001$ & .0020 & $(.0013, .0026)$ & .0882 & $<.001$ \\
\hline $\begin{array}{l}\text { Constant } \\
\mathrm{N} \\
\text { Adjusted } \mathrm{R}^{2}\end{array}$ & $\begin{array}{l}.0130 \\
4874 \\
.29\end{array}$ & $(.7433,1.2827)$ & - & $<.001$ & $\begin{array}{l}.0723 \\
4874 \\
.13\end{array}$ & $(-.0590, .2035)$ & - & .281 \\
\hline
\end{tabular}

\section{Moderation Models}

\begin{tabular}{|c|c|c|c|c|c|c|c|c|}
\hline Neighbourhood greenspace (\%) & -.0006 & $(-.0052, .0040)$ & -.0077 & .800 & -.0012 & $(-.0035, .0010)$ & -.0366 & .280 \\
\hline Nature visits ( $\geq$ once a week) & .2682 & $(.1050, .4314)$ & .0915 & .001 & -.0578 & $(-.1366, .0210)$ & -.0452 & .151 \\
\hline Nature progs. TV/radio (Yes) & .4981 & $(.3323, .6640)$ & .1731 & $<.001$ & -.1192 & $(-.1994,-.0389)$ & -.0951 & .004 \\
\hline Nature connectedness $(\%, \mathrm{NC})$ & .0070 & $(.0025, .0115)$ & .1374 & .002 & -.0006 & $(-.0028, .0015)$ & -.0288 & .564 \\
\hline Greenspace x NC & .0000 & $(.0000, .0001)$ & .0460 & .378 & .0000 & $(.0000, .0000)$ & .0230 & .690 \\
\hline Visits $\times \mathrm{NC}$ & .0013 & $(-.0012, .0037)$ & .0327 & .319 & .0013 & $(.0001, .0024)$ & .0747 & .040 \\
\hline Nature progs. $x \mathrm{NC}$ & .0030 & $(.0005, .0055)$ & .0792 & $<.001$ & .0032 & $(.0020, .0044)$ & .1930 & $<.001$ \\
\hline Constant & 1.2523 & $(.8806,1.6240)$ & - & $<.001$ & .2300 & $(.0498, .4101)$ & - & .012 \\
\hline $\mathrm{N}$ & 4874 & & & & 4874 & & & \\
\hline Adjusted $\mathrm{R}^{2}$ & .29 & & & & .13 & & & \\
\hline Delta $R^{2}$ & .00 & & & & .00 & & & \\
\hline
\end{tabular}

Note: $\mathrm{NC}=$ Nature connectedness. Controls included in these models: Area level -urbanicity, deprivation; Individual level - age, gender, socioeconomic status, employment status, household composition, ethnicity, survey year; related outcome variables (See Tables S6a-

$\mathrm{S} 7 \mathrm{~b}$ for details). Delta $\mathrm{R}^{2}$ reflects the adjusted $\mathrm{R}^{2}$ change between the initial and moderation models. 
nature connectedness score of 1 standard deviation above the mean (29.95\%) were substantially larger than the increase associated with being female vs. male $(6.76 \%)$. Watching/listening to nature programmes and having a nature connectedness score of 1 standard deviation above the mean also exceeded the increase in household behaviours associated with having a high vs. low socio-economic status $(24.41 \%)$. For nature conservation behaviours, the increase associated with watching/listening to nature programmes $(29.79 \%)$ was almost half the size of the increase associated with having higher vs. lower socio-economic status (76.36\%). Having a nature connectedness score of 1 standard deviation above the mean, was associated with an increase in nature conservation behaviours roughly one third (46.81\%) smaller than the increase associated with having higher vs. lower socio-economic status.

3.3 Main findings: Moderation effects by nature connectedness (Table 3)

Incidental contact: no additional moderation effects of nature connectedness were found for the associations between living near greenspace and either health/wellbeing or pro-environmental behaviour outcomes.

Intentional contact: for nature visits significant interactions were observed for both eudaimonic wellbeing and nature conservation behaviours. The positive relationship between nature connectedness and eudaimonic wellbeing was stronger for those who visited natural spaces at least once a week. At low levels of connectedness 
Table 4: Estimated Marginal Means and Percentage Difference in outcome variables as a function of nature contact, nature connectedness and socio-demographic comparators.

\begin{tabular}{|c|c|c|c|c|c|c|c|c|}
\hline 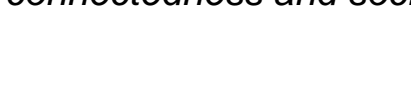 & \multicolumn{2}{|c|}{ General Health } & \multicolumn{2}{|c|}{$\begin{array}{l}\text { Eudaimonic Wellbeing } \\
\text { (worthwhile activities) }\end{array}$} & \multicolumn{2}{|c|}{ Household PEB } & \multicolumn{2}{|c|}{ Nature Conservation PEB } \\
\hline & EMM & $\%$ difference & EMM & $\%$ difference & EMM & $\%$ difference & EMM & $\%$ difference \\
\hline $\begin{array}{l}\text { Neighbourhood greenspace } \\
1 \text { SD below Mean }(45.68 \%) \\
1 \text { SD above Mean }(83.08 \%)\end{array}$ & $\begin{array}{l}3.94 \\
3.86\end{array}$ & $-2.05 \%$ & $\begin{array}{l}7.72 \\
7.75\end{array}$ &. & $\begin{array}{l}2.05 \\
2.10\end{array}$ & $2.41 \%$ & $\begin{array}{l}.25 \\
.22\end{array}$ & $-12.77 \%$ \\
\hline $\begin{array}{l}\text { Nature visits } \\
<\text { once a week } \\
\geq \text { once a week }\end{array}$ & $\begin{array}{l}3.78 \\
3.98\end{array}$ & $5 . \overline{-}$ & $\begin{array}{l}7.70 \\
7.76\end{array}$ & - & $\begin{array}{l}1.87 \\
2.22\end{array}$ & $17 . \overline{-}$ & $\begin{array}{l}.22 \\
.24\end{array}$ & $8 . \overline{-}$ \\
\hline $\begin{array}{l}\text { Nature progs. TV/radio } \\
\text { No } \\
\text { Yes }\end{array}$ & $\begin{array}{l}3.91 \\
3.90\end{array}$ & $-.26 \%$ & $\begin{array}{l}7.70 \\
7.77\end{array}$ & $.90 \%$ & $\begin{array}{l}1.73 \\
2.41\end{array}$ & $32.85 \%$ & $\begin{array}{l}.20 \\
.27\end{array}$ & $29.79 \%$ \\
\hline $\begin{array}{l}\text { Nature connectedness } \\
1 \mathrm{SD} \text { below mean }(31.85) \\
1 \mathrm{SD} \text { above mean (88.39) }\end{array}$ & $\begin{array}{l}3.90 \\
3.91\end{array}$ & $.26 \%$ & $\begin{array}{l}7.48 \\
7.99\end{array}$ & $6.59 \%$ & $\begin{array}{l}1.76 \\
2.38\end{array}$ & $29.95 \%$ & $\begin{array}{l}.18 \\
.29\end{array}$ & $46 . \overline{81 \%}$ \\
\hline $\begin{array}{l}\text { Gender } \\
\text { Male } \\
\text { Female }\end{array}$ & $\begin{array}{l}3.91 \\
3.90\end{array}$ & $-.26 \%$ & $\begin{array}{l}7.69 \\
7.77\end{array}$ & $1.03 \%$ & $\begin{array}{l}2.00 \\
2.14\end{array}$ & $6.76 \%$ & $\begin{array}{l}.25 \\
.22\end{array}$ & $-12.77 \%$ \\
\hline $\begin{array}{l}\text { Social grade } \\
D E \\
A B\end{array}$ & $\begin{array}{l}3.84 \\
3.96\end{array}$ & $3.08 \%$ & $\begin{array}{l}7.68 \\
7.81\end{array}$ & $1 . \overline{-}$ & $\begin{array}{l}1.87 \\
2.39\end{array}$ & $24 . \overline{-} 1 \%$ & $\begin{array}{l}.17 \\
.38\end{array}$ & $76 . \overline{36 \%}$ \\
\hline
\end{tabular}


eudaimonic wellbeing was higher amongst those that made weekly visits (vs. < once a week), but at high levels of connectedness there was no longer any difference (Figure 1a). The opposite pattern was observed for nature conservation behaviours, where the association between nature connectedness and these behaviours was stronger for those who visited at least weekly (Figure 1b).

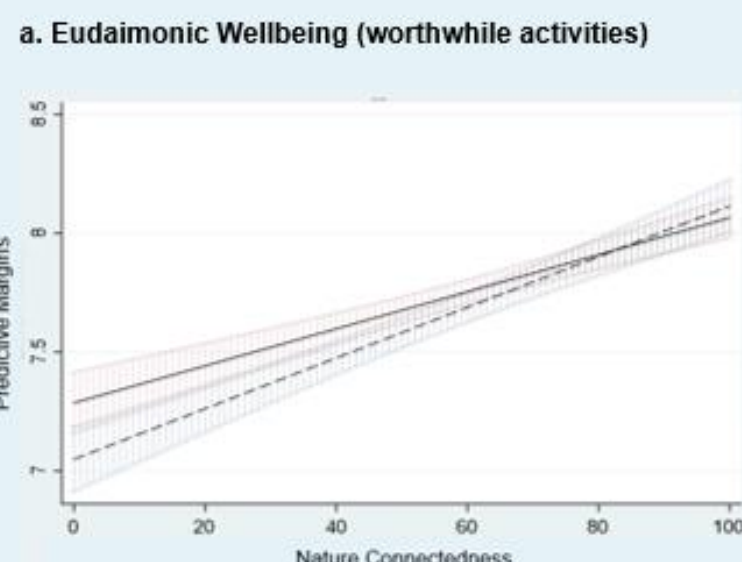

Nature visits: b. Nature Conservation Behaviours

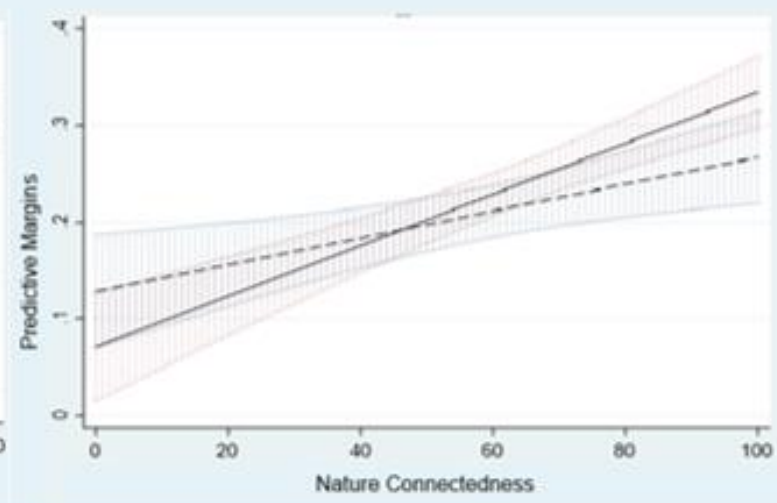

Figure 1: Predictive margins for eudaimonic wellbeing and nature conservation behaviours, as a function of nature visits and nature connectedness.

Indirect contact: perhaps the clearest moderation patterns emerged between nature connectedness and the propensity to watch/listen to nature programmes.

Specifically, significant interactions emerged for both wellbeing and both proenvironmental outcomes (Table 3). In terms of evaluative wellbeing, for individuals who did not watch nature programmes, nature connectedness had little impact upon life satisfaction (Figure 2a). Conversely, amongst those that watched nature programmes, life satisfaction decreased as nature connection increased. For 
eudaimonic wellbeing, the association between nature connectedness and this facet of subjective wellbeing was stronger for those who did vs. did not report watching/listening to nature programmes (Figure $2 b$ ).
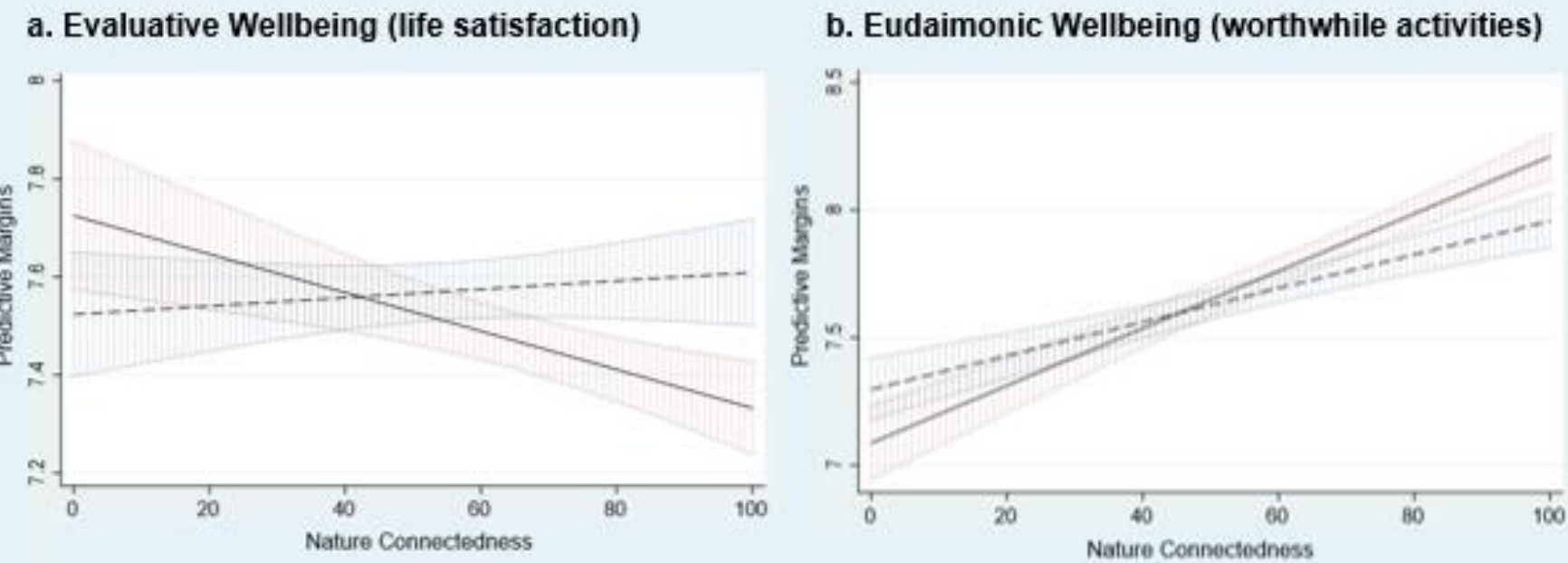

c. Household Pro-Environmental Behaviours

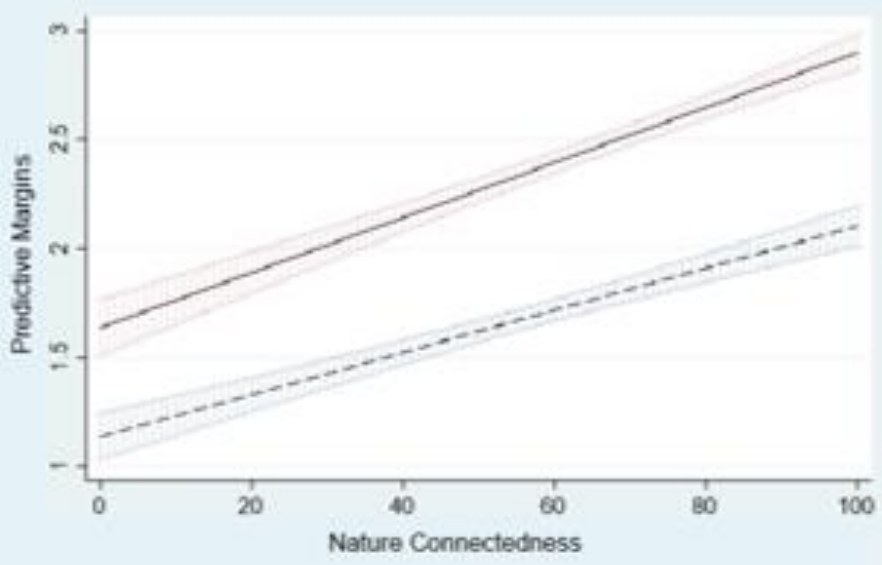

d. Nature Conservation Behaviours

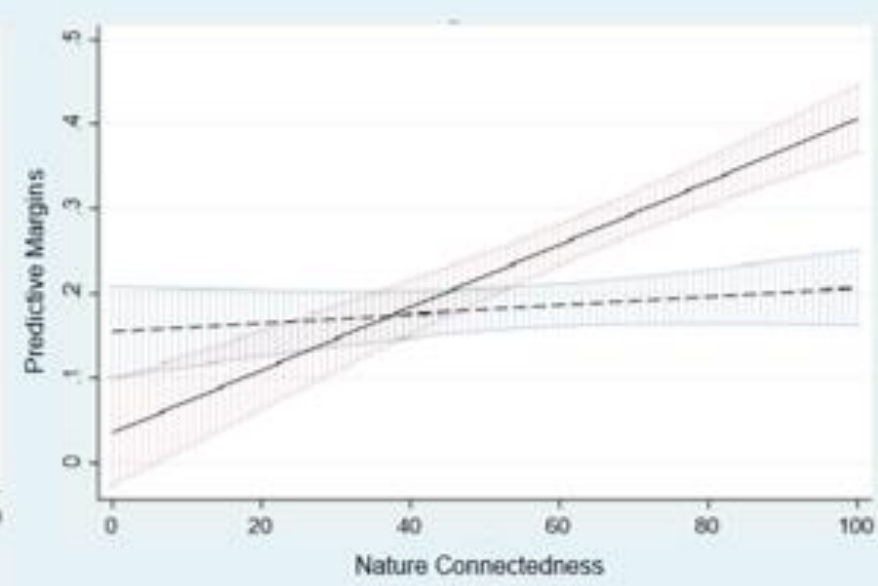

Nature programmes: -... No - Yes

Figure 2: Predictive Margins for Wellbeing and Pro-environmental outcomes as a function of nature programmes and nature connectedness.

Regarding pro-environmental outcomes, individuals who watched nature programmes reported more household conservation behaviours than those who did 
not, and this pattern became more marked as nature connectedness increased (Figure 2c). For nature conservation behaviours, for individuals who did not watch nature programmes, nature connectedness had little impact upon conservation behaviours (Figure 2d). Conversely, amongst those that watched nature programmes, conservation behaviours increased as nature connectedness increased in a similar fashion (i.e. slope) to household behaviours. In sum, there were positive synergistic effects of nature connectedness and watching/listening to nature programmes for three of our five outcomes, and one antagonistic effect on evaluative wellbeing/life satisfaction.

\section{Discussion}

Growing detachment from the natural world may be a factor in poor mental and physical health (Twohig-Bennett \& Jones, 2018; Lovell, Depledge \& Maxwell, 2018; Capaldi et al. 2014) as well as a reduced propensity for environmentally sustainable behaviours (Weinstein et al., 2015; Zelenski, et al. 2015). Using a representative sample of the adult population of England and a cross-sectional design, the current study investigated the associations between three types of nature contact and nature connectedness and a range of health, well-being and pro-environmental outcomes.

\subsection{Summary of results}

\subsubsection{Incidental contact: Living near greenspace.}

Neighbourhood greenspace was negatively related to general health and unrelated to any of the subjective wellbeing or pro-environmental outcomes.

Evidence of positive associations in previous research has also been mixed (Hartig et al., 2014; Frumkin et al., 2017, White et al., 2017), possibly because quantity 
metrics such as those used here do not account for quality (Van Dillen, de Vries, Groenewegen \& Spreeuwenberg, 2012; Francis, Wood, Knuiman \& Giles-Corti, 2012). Indicators of the quality of greenspace should be included in future research, where possible. It is also possible that the mere presence of greenspace is simply not very important, whereas visiting greenspaces, i.e. taking active decision to go outside, is the key factor. Indeed, previous analysis of a different set of MENE data observed that people in England living in the least green areas spend significantly more time in nature than those living in greener areas, contrary to common assumptions about greener areas facilitating more time in nature (White et al., 2019, Supplementary table S2), emphasising the importance of distinguishing between presence and use of greenspace. We know of no previous work that has explored area level nature and pro-environmental behaviours. We found no association of living near greenspace and pro-environmental behaviours, at least in England.

\subsubsection{Intentional contact: Nature visits.}

Visiting natural spaces at least once a week (vs. less frequent visits) was positively associated with general health. Although consistent with studies observing higher levels of perceived health amongst individuals who intentionally spend time in nature (White et al., 2019; Soga et al., 2017; Rappe, Kivelä \& Rita, 2006), our findings extend prior research in two ways. Firstly, this is the first study, to our knowledge, that has observed this association whilst controlling for other types of nature contact and nature connectedness. Our findings suggest that environmental practices and policies, which encourage visits to natural spaces, may be important to translate the accessibility of greenspace into discernible improvements to health. Secondly, the effect size of weekly visits was larger than that of belonging to a higher 
socio-economic group. Given the recognised importance of this factor for health, we interpret the size of the visit frequency relationship to be practically meaningful in terms of public health, but more research on causality is needed.

The frequency of visits to natural spaces, however, was unrelated to either of our wellbeing outcomes in initial models and only to eudaimonic well-being in moderation models. The findings for evaluative wellbeing are consistent with prior research using a different sub-sample of the MENE survey, which also failed to find a significant relationship, but the lack of a positive association between nature visits and eudaimonic wellbeing are more surprising (White et al., 2017). The divergent findings between studies may relate to the inclusion of nature connectedness within our models, but not those of White et al., (2017). Our moderation effects are potentially telling here: they suggest that more frequent weekly visits ( $v s$. less frequent) to natural spaces were only associated with higher eudaimonic wellbeing for individuals who felt less connected to nature. This finding is broadly consistent with intervention studies reporting individuals with lower nature connectedness benefit most from engaging with natural environments (Richardson et al., 2018).

Regarding pro-environmental behaviours, visiting natural spaces at least once a week was associated with a higher propensity to engage in more common household pro-environmental behaviours, such as recycling and buying ecological products. This finding is consistent with both empirical evidence and theory suggesting that direct contact with nature can promote ecological attitudes and behaviours (Hartig et al., 2001; Lawrence, 2012). With no main effect of visit frequency on nature-conservation behaviours, the benefit of weekly nature visits did not extend to pro-environmental behaviours involving other investment in environmental issues (e.g. volunteering). As indicated by the moderation effect, 
weekly visits alone were not sufficient to encourage conservation behaviours, individuals also needed to feel an affinity towards nature, in order to protect it.

\subsubsection{Indirect contact: Watching/listening to nature programmes.}

Experimental research has demonstrated better wellbeing (White et al., 2018) and sustainability outcomes (Arendt \& Matthes 2016; Zelenski, Dopko \& Capaldi, 2015) as a result of indirect exposure to nature under controlled conditions (e.g. videos or virtual reality). Relatively little research has examined naturalistic indirect exposures, such as whether individuals report watching or listening to programmes about natural environments in their every-day lives. That watching/listening to nature programmes was associated with lower evaluative wellbeing in such settings can perhaps be explained by psychological wellbeing being generally lower among people who watch more television (e.g. Hamer, Stamatakis, \& Mishra, 2010). The interaction term is also potentially telling: since nature documentaries may feature information about environmental degradation, we could speculate that exposure to such information may cause individuals who feel highly connected to nature to feel less satisfied with life. Indeed, increased awareness of environmental issues, in general, is negatively associated with life satisfaction (Ferrer-i-Carbonell \& Gowdy, 2007).

With research showing that aspects of personal identity predict perceptions of meaningfulness (Baumeister, Vohs, Aaker \& Garbinsky, 2013) the moderation effect observed for eudaimonic wellbeing is also somewhat intuitive. That is, individuals who score highly on trait connectedness, may consider their activities in life more worthwhile, when they include watching or listening to nature programmes in this list of activities. Conversely, individuals less connected to nature experience higher 
eudaimonic wellbeing in the absence of nature programmes. Although, given the novelty of these effects, further research is needed to see whether they are replicable and, if so, what may be underpinning them.

Extending previous experimental findings (Zelenski, Dopko, \& Capaldi, 2015) but using a more naturalistic measure of indirect nature contact, we found that watching/listening to nature programmes was positively related to both types of proenvironmental outcome. Further, for household pro-environmental behaviours, the strength of this association was considerably stronger than that of visiting natural spaces, as well as benchmark socio-demographics that are less amenable to change (e.g. being female or belonging to a higher socio-economic group). Congruent with prior research (Arendt \& Matthes, 2016), the moderation effects observed suggested that the associations between nature programmes and proenvironmental outcomes were stronger for individuals who were most highly connected to nature. Nevertheless, causal directionality is unclear and it may also be the case that people who begin to engage in more pro-environmental behaviours, e.g. due to external circumstances such as the introduction of a new doorstep recycling scheme, may start to become more interested in nature related topics (for a discussion of environmental 'spillover effects' see Truelove, Carrico, Weber, Raimi \& Vandenbergh, 2014).

\subsubsection{Nature Connectedness}

Previous literature on nature connectedness indicates positive relationships with aspects of wellbeing (Capaldi, Dopko \& Zelenski, 2014; Pritchard, Richardson, Sheffield \& McEwan, 2019) and pro-environmental behaviours (Mackay \& Schmitt, 2019; Whitburn, Linklater \& Abrahamse, 2019). Extending previous work, positive 
associations observed in the current research between nature connectedness and both eudaimonic wellbeing and pro-environmental behaviours remained after accounting for: a) various types of nature exposure, and b) a comprehensive range of socio-demographics. Therefore, the role of psychological connectedness is important over and above nature contact for these outcomes. Furthermore, for eudaimonic wellbeing and household pro-environmental behaviours, these effects are likely to be practically meaningful, given that they were greater in magnitude to benchmark socio-demographic factors.

As outlined above, individual differences in trait nature connectedness also moderated the associations between specific types of nature contact and some of our well-being and pro-environmental outcomes. Therefore, our findings extend prior theory and research that focused on the mediating role of state connectedness (Mayer, Frantz, Bruehlman-Senecal \& Dolliver, 2009; Whitburn, Linklater \& Milfont, 2018), demonstrating that trait nature connectedness appears to modify the way in which individuals respond to contact with the natural world (Arendt \& Matthes, 2016; Ojala, 2009).

\subsection{Limitations}

Our results should to be considered within the context of several limitations. First, the results are based on cross-sectional survey data, limiting inferences of causal direction. We suspect that contact and connectedness are likely to be selfreinforcing and thus bidirectional, e.g. growing nature connectedness may increase pro-environmental behaviours or wellbeing which in turn reinforces feelings of connectedness (e.g. Wyles et al. 2019). 
Second, results are based on self-report data. There is good evidence that selfreported health and wellbeing correlate strongly with objective indices (Diener, Suh, Lucas, \& Smith, 1999; Kyffin, Goldacre, Gill, 2004), although we should perhaps be more cautious about self-reported pro-environmentalism (Kormos \& Gifford, 2014). There is less clarity regarding the accuracy of self-reported visit frequency or nature programme viewing so we are unsure whether there are any biases inherent within these measures.

Third, the current survey data was collected several years after the neighbourhood greenspace data which was assigned to individuals based on the LSOA of their current residence. Consequently, it may be that levels of neighbourhood greenspace actually experienced at the time of self-reported outcomes differed from the values used here, which may have added error to our models. Ideally, future work would have temporally consistent exposure and outcome metrics, although this is not always easy to establish, especially at the national scale explored here.

Fourth, we recognise that we know little about the quality of contact with nature in our measures (e.g. White et al., 2013). Someone may visit nature frequently to walk their dog (White et al., 2018) but this contact may occur in ecologically impoverished urban parks or while engaged in other activities, resulting in diminished awareness of, or engagement with surroundings. This is important for two reasons. Firstly, recent research suggests higher subjective wellbeing is associated with visits to higher quality nature settings (Wyles et al., 2019). Secondly, the quality of the interaction is also determined by the activity, for example interventions to notice the 'good things' in nature have been found to increase nature connectedness and 
psychological well-being (Richardson \& Sheffield, 2017). Future work is needed to explore this in more detail.

Fifth, results are based on the set of covariates available in the associated waves of the MENE dataset. Unfortunately, variables including the amount of physical activity undertaken per week, and the existence of a long-term limiting illness were not available in the waves containing the $\mathrm{NCl}$ measure. Thus, unlike previous MENE studies that have controlled for these factors, we were unable to do so here. It would be useful to investigate whether our findings continue to hold using future waves of data when these variables are returned to the dataset.

Sixth, we recognise that these data are only representative of the current adult population of England and further work is needed to see whether similar effects are found in other countries and among children, a growing focus of research in the nature connectedness field (Cheng, \& Monroe, 2012).

Finally, the effect sizes for our key predictors were small. This is concerning in that it suggests nature-related factors are only accounting for a limited amount of variance in our key outcomes. However, our comparative approach demonstrated that nature-related factors were often as important, and in some cases more important, than socio-demographic factors such as gender and socio-economic status. Although many potentially relevant predictors were not included in the MENE dataset, and thus could not be included in our models, the relatively low levels of overall variance explained still suggest we have much to learn about what factors influence health, well-being and pro-environmental behaviour.

\subsection{Implications}


Specific types of nature contact, as well as stable individual differences in nature connectedness, were differentially associated with aspects of health, well-being and pro-environmental behaviours. This pattern of findings has implications for future theory and research. First, regarding the operationalisation of nature contact, existing theory and research tends to be underpinned by the assumption that exposure to greenspace is beneficial, regardless of the type of contact (Wheeler et al., 2015; Bell, Phoenix, Lovell \& Wheeler, 2014). There is undeniable evidence that diverse interactions with nature are associated with analogous outcomes (TwohigBennett \& Jones, 2018; McMahan \& Estes, 2015; Weinstein et al., 2015). However, our findings illustrate the risks of equating heterogeneous conceptualisations of nature contact with equivalent health, wellbeing and sustainability outcomes, in the context of large-scale, cross-sectional research. For instance, although studies examining the impacts of specific types of nature contact have many merits, without accounting for different types of interactions for nature at the same time, they may over-inflate the associations between a specific type of contact and outcome variables. Additionally, our findings for pro-environmental behaviours suggest that multiple types of nature contact are simultaneously associated with positive outcomes, and such additive effects may go undetected in studies that only examine the impact of a singular contact type.

Second, the relevance of person-specific factors in human-nature interactions has largely been overlooked in previous theory and research. That individual differences in trait nature connectedness were associated with eudaimonic wellbeing and proenvironmental behaviours, after accounting for nature contact and sociodemographics, illustrates their predictive value. Further, our moderation effects indicate that trait nature connectedness influences the way in which individuals 
respond to contact with the natural world. Taken together, our findings suggest that adopting a more nuanced approach to the study of human-nature interactions is likely to be necessary to understand these complexities better and subsequently inform policies that are beneficial to both human and planetary health.

Third, our findings are particularly relevant to practitioners and policy makers because of the nationally representative nature of the sample (Natural England, 2018), as well as the realistic and diverse types of nature contact respondents had. Several key messages emerged. First, visiting nature at least once a week was positively associated with key policy goals such as better general health and more pro-environmental behaviours. This advocates the need to protect and invest in pressured natural resources, in order to maximise the health and sustainability benefits that they afford. Moreover, policies that improve accessibility and support people to get out into natural environments are likely to play a key part in achieving health and sustainability objectives. Second, there were strong relationships between watching/listening to nature programmes and pro-environmentalism, supporting the potential role of this kind of indirect contact in attitudes and behaviour. If our findings are substantiated by future experimental and/or longitudinal research that is better able to demonstrate directionality, then this type of nature contact may be particularly pertinent for individuals with limited access to natural places.

Fourth, psychological connectedness to nature was a key factor, not just in terms of its direct associations with different types of pro-environmental behaviour but also through its moderating effects on intentional and indirect nature contact. For instance, for eudaimonic wellbeing, visit frequency and nature connectedness interacted, suggesting optimal visits may be those that activate the pathways to nature connectedness (Lumber et al., 2017). Interventions could be designed to 
encourage this process, by, for instance, embedding efforts to stimulate nature connectedness within nature-based activities. At the very least, our data support the value of collecting information on nature connectedness at the national-level and encouraging interventions that increase it among the population (Richardson et al, 2018; Richardson, Hallam, \& Lumber, 2015).

Finally, household pro-environmental behaviours, such as recycling, were far more frequent in our sample than nature-conservation behaviours (e.g. volunteering), with the latter potentially requiring more commitment and effort (Bamberg \& Moser, 2007; Steg and Vlek, 2009). It is thus potentially important to note that while the main effect associations with nature connectedness were stronger for household than conservation behaviours, the interaction effects were stronger for conservation than household behaviours. This suggests that efforts to build connectedness may be particularly important for these more challenging behaviours.

\subsection{Concluding comments}

Globally there is trend for people losing touch with the natural world (Soga \& Gaston, 2016) at the very moment when research is demonstrating just how dependent human health and wellbeing is on natural ecosystems. The current research broadly supports the contention that maintaining contact with nature is positively related to both an individual's own health and wellbeing and their propensity to act in ways that protect the health of the planet. Moreover, we found several instances where associations between outcomes and the same levels of contact were moderated by psychological connectedness with nature. Thus, nature 
contact may be more effective if accompanied by a positive disposition towards the environment.

Although the current research was unable to establish how such a disposition could be developed and confirm the causality of this link, we look forward to seeing the results of initiatives to build connectedness in both children and adults in terms of their effects on health, wellbeing and pro-environmentalism, in due course. We also observed intriguing associations between watching/listening to nature programmes and a range of outcomes. We found that people with high nature connectedness reported lower life satisfaction when they consumed nature programmes. Further research should investigate under which circumstances nature programmes may help or hinder well-being outcomes. On the other hand, people who consumed more nature programmes reported higher pro-environmental behaviour. Far from being the enemy of the natural world, it may be that appropriate screen-time might offer important environmental protection opportunities.

In the face of rapid urbanisation, it is becoming increasingly important to understand how contact with, and psychological connection to pressured natural resources, are linked to indicators of human health and sustainable behaviour. We aimed to overcome the evident fragmentation within the current literature by integrating key concepts from health and sustainability research agendas. The complexity of our findings suggests that interventions increasing both contact with, and connection to nature, are likely to be needed in order to achieve synergistic improvements to human and planetary health 


\section{Acknowledgements}

This research was supported by an interdisciplinary Working Group drawn from Natural England's Strategic Research Network for People and the Natural Environment and National Outdoors for All Working Group. We thank the following colleagues for their involvement in developing, supporting and delivering the wider project that has enabled this data analysis: Nigel Doar (Royal Society of Wildlife Trusts), Dr. Joelene Hughes and Amy Batchelor (Royal Society for the Protection of Birds), Alex Hunt, Penelope Chapple, and Tate Greenhalgh (National Trust), Hannah Fluck (Historic England), Duncan Stewart and Russel Bradshaw (Kantar TNS), Dr. Rachel Bragg (University of Essex/Care Farming UK), Dr. Joe Hinds (University of Greenwich), Dr. Kayleigh Wyles (University of Surrey), Professor Catharine Ward Thompson (University of Edinburgh), Dr. Eric Brymer (Leeds Beckett University) and Dr. Valerie Gladwell and Dr. Jo Barton (University of Essex). We also acknowledge the support of the Economic and Social Research Council (ESRC) who funded the first author's contribution to this research through the South West Doctoral Training Partnership Placement Scheme, linked to PhD studentship funding awarded to the University of Plymouth. 


\section{References:}

Alcock I, White M, Taylor T, Coldwell D, Gribble M, et al. (2017). 'Green' on the ground but not in the air: Pro-environmental attitudes are related to household behaviours but not discretionary air travel. Global Environmental Change 42, 136-147.

Arendt, F., \& Matthes, J. (2016). Nature documentaries, connectedness to nature, and pro-environmental behavior. Environmental Communication, 10(4), 453-472.

Bamberg, S., \& Möser, G. (2007). Twenty years after Hines, Hungerford, and Tomera: A new meta-analysis of psycho-social determinants of pro-environmental behaviour. Journal of Environmental Psychology, 27(1), 14-25.

Baumeister, R. F., Vohs, K. D., Aaker, J. L., \& Garbinsky, E. N. (2013). Some key differences between a happy life and a meaningful life. The journal of positive psychology, 8(6), 505-516. 
Bell, S. L., Phoenix, C., Lovell, R., \& Wheeler, B. W. (2014). Green space, health and wellbeing: Making space for individual agency. Health \& Place, 30, 287-292.

Bringslimark, T., Hartig, T., \& Patil, G. G. (2009). The psychological benefits of indoor plants: A critical review of the experimental literature. Journal of Environmental Psychology, 29(4), 422-433.

Capaldi, C. A., Dopko, R. L., \& Zelenski, J. M. (2014). The relationship between nature connectedness and happiness: a meta-analysis. Frontiers in Psychology, 5, 976.

Capaldi, C. A., Passmore, H. A., Nisbet, E. K., Zelenski, J. M., \& Dopko, R. L. (2015). Flourishing in nature: A review of the benefits of connecting with nature and its application as a wellbeing intervention. International Journal of Wellbeing, 5(4).

Cheng, J. C. H., \& Monroe, M. C. (2012). Connection to nature: Children's affective attitude toward nature. Environment and Behavior, 44(1), 31-49.

Clayton, L. W. (2003). Identity and the natural environment: The psychological significance of nature. Mit Press. 
Cox, D. T., Hudson, H. L., Shanahan, D. F., Fuller, R. A., \& Gaston, K. J. (2017). The rarity of direct experiences of nature in an urban population. Landscape and urban planning, 160, 79-84.

Cummins, R. A., Eckersley, R., Pallant, J., Van Vugt, J., \& Misajon, R. (2003). Developing a national index of subjective wellbeing: The Australian Unity Wellbeing Index. Social indicators research, 64(2), 159-190.

Dadvand, P., Bartoll, X., Basagaña, X., Dalmau-Bueno, A., Martinez, D., Ambros, A., ... \& Nieuwenhuijsen, M. J. (2016). Green spaces and general health: roles of mental health status, social support, and physical activity. Environment International, 91, 161-167.

Depledge, M.H., White, M.P., Maycock, B., \& Fleming, L.E. (2019).Time and tide: Our future health and well-being depends on the Oceans. British Medical Journal, $366: 14671$

Diener, E., Suh, E. M., Lucas, R. E., \& Smith, H. L. (1999). Subjective well-being: Three decades of progress. Psychological bulletin, 125(2), 276.

Ferrer-i-Carbonell, A., \& Frijters, P. (2004). How Important is Methodology for the Estimates of the determinants of Happiness? The Economic Journal,114, 641-659.

Francis, J., Wood, L. J., Knuiman, M., \& Giles-Corti, B. (2012). Quality or quantity? Exploring the relationship between Public Open Space attributes and mental health in Perth, Western Australia. Social science \& medicine, 74(10), 1570-1577. 
Frumkin, H., Bratman, G. N., Breslow, S. J., Cochran, B., Kahn, P. H., Lawler, J. J., Levin, P.S., Tandon, P.S., Varanasi, U., Wolf, K.L. \& Wood, S. A. (2017). Nature contact and human health: A research agenda. Environmental Health Perspectives, 125(7).

Gascón, M., Zijlema, W. Vert, C., White, M.P., \& Nieuwenhuijsen, M.J. (2017). Blue spaces, human health and well-being: a systematic review. International Journal of Hygiene and Environmental Health, 1207-1221.

Gifford, R. (2014). Environmental psychology matters. Annual review of psychology, 65, 541-579.

Graham, H., \& White, P. C. L. (2016). Social determinants and lifestyles: integrating environmental and public health perspectives. Public health, 141, 270-278.

Grinde, B., \& Patil, G. (2009). Biophilia: does visual contact with nature impact on health and well- being?. International Journal of Environmental Research and Public Health, 6(9), 2332-2343.

Hamer, M., Stamatakis, E., \& Mishra, G. D. (2010). Television-and screen-based activity and mental well-being in adults. American journal of preventive medicine, 38(4), 375-380.

Hartig T, Kaisser FG and Bowler PA (2001). Psychological restoration in nature as a positive motivation for ecological behaviour. Environment and Behavior 33, 590-607. 
Hartig, T., Mitchell, R., De Vries, S., \& Frumkin, H. (2014). Nature and health. Annual Review of Public Health, 35, 207-228.

Hartig, T., Kaiser, F. G., \& Strumse, E. (2007). Psychological restoration in nature as a source of motivation for ecological behaviour. Environmental conservation, 34(4), 291-299.

Hunt, A., Stewart, D., Richardson, M., Hinds J., Bragg, R., White, M. and Burt, J. (2017). Monitor of Engagement with the Natural Environment: developing a method to measure nature connectedness across the English population (adults and children). Natural England Commissioned Reports, Number 233. York.

Jokela, M. (2015). Does neighbourhood deprivation cause poor health? Within-individual analysis of movers in a prospective cohort study. Journal of Epidemiology Community Health, 69(9), 899-904.

Keniger, L.E., Gaston, K.E., Irvine, K.N. \& Fuller, R.A. (2013). What are the Benefits of Interacting with Nature? International Journal of Environmental Research and Public Health, 10, 913-935.

Kormos, C., \& Gifford, R. (2014). The validity of self-report measures of proenvironmental behavior: A meta-analytic review. Journal of Environmental Psychology, 40, 359371. 
Kyffin, R.G., Goldacre, M.J., Gill, M., (2004). Mortality rates and self-reported health: database analysis by English local authority area. British Medical Journal (Clinical Research Edition), 329, 887-888.

Lawrence, E. K. (2012). Visitation to natural areas on campus and its relation to place identity and environmentally responsible behaviors. The Journal of Environmental Education, 43(2), 93-106.

Lovell, R., Depledge, M \& Maxwell, S. (2018). Health and the natural environment: A review of evidence, policy, practice and opportunities for the future. Retrieved from: http://randd.defra.gov.uk.

Lumber, R., Richardson, M., \& Sheffield, D. (2017). Beyond knowing nature: Contact, emotion, compassion, meaning, and beauty are pathways to nature connectedness. PloS one, 12(5), e0177186.

Lumley, T., Diehr, P., Emerson, S., \& Chen, L. (2002). The importance of the normality assumption in large public health data sets. Annual review of public health, 23(1), 151-169.

Mackay, C. M., \& Schmitt, M. T. (2019). Do people who feel connected to nature do more to protect it? A meta-analysis. Journal of Environmental Psychology, 65, 101323. 
Markevych, I., Schoierer, J., Hartig, T., Chudnovsky, A., Hystad, P., Dzhambov, A. M., ... \& Lupp, G. (2017). Exploring pathways linking greenspace to health: Theoretical and methodological guidance. Environmental Research, 158, 301-317.

Martin, C. \& Czellar, S. (2016). The extended Inclusion of Nature in Self scale. Journal of Environmental Psychology, 47, 181-194. Mayer, F.S., Frantz, C.M., BruehlmanSenecal, E., Dolliver, K. (2009). Why is nature beneficial?: the role of connectedness to nature. Environmental Behaviour. 41, 607-643.

Mayer, F. S., \& Frantz, C. M. (2004). The connectedness to nature scale: A measure of individuals' feeling in community with nature. Journal of environmental psychology, 24(4), 503-515.

Mayer, F. S., Frantz, C. M., Bruehlman-Senecal, E., \& Dolliver, K. (2009). Why is nature beneficial? The role of connectedness to nature. Environment and behavior, 41(5), 607-643.

McMahan, E. A., \& Estes, D. (2015). The effect of contact with natural environments on positive and negative affect: A meta-analysis. The Journal of Positive Psychology, 10, 507-519.

Meyer, O. L., Castro-Schilo, L., \& Aguilar-Gaxiola, S. (2014). Determinants of mental health and self-rated health: a model of socioeconomic status, neighborhood safety, and physical activity. American journal of public health, 104(9), 1734-1741. 
Natural England. (2018). Monitor of Engagement with the Natural Environment: Headline reports and technical reports 2016-2017 to 2017-2018. Retrieved from: www.gov.uk/government/statistics/monitor-of-engagement-with-the-naturalenvironment-headline-reports-and-technical-reports-2016-2017-to-2017-2018.

Nisbet, E. K., \& Gick, M. L. (2008). Can health psychology help the planet? Applying theory and models of health behaviour to environmental actions. Canadian Psychology/Psychologie canadienne, 49(4), 296.

Nisbet, E. K., Zelenski, J. M., \& Murphy, S. A. (2009). The nature relatedness scale: Linking individuals' connection with nature to environmental concern and behavior. Environment and Behavior, 41(5), 715-740.

Nutsford, D., Pearson, A. L., Kingham, S., \& Reitsma, F. (2016). Residential exposure to visible blue space (but not green space) associated with lower psychological distress in a capital city. Health \& Place, 39, 70-78

Office for National Statistics (2017). Leisure time in the UK: 2015. Retrieved from: https://www.ons.gov.uk/economy/nationalaccounts/satelliteaccounts/articles/leisureti meintheuk/2015

Office of the Deputy Prime Minister. (2005). Generalised Land Use Database Statistics for England. London

Ojala, A. (2009). The interaction between emotional connectedness to nature and leisure activities in predicting ecological worldview. Umweltpsychologie, 13, 10-22. 
Pritchard, A., Richardson, M., Sheffield, D., \& McEwan, K. (2019). The relationship between nature connectedness and eudaimonic well-being: A meta-analysis. Journal of Happiness Studies, 1-23.

Rappe, E., Kivelä, S. L., \& Rita, H. (2006). Visiting outdoor green environments positively impacts self-rated health among older people in long-term care. HortTechnology, 16(1), 55-59.

Rawlinson, K. (2017). Michael Gove 'haunted' by plastic pollution seen in Blue Planet II. Retrieved from: https://www.theguardian.com/environment/2017/dec/19/michaelgove-haunted-by-plastic-pollution-seen-in-blue-planet-ii

Richardson, M., Hallam, J., \& Lumber, R. (2015). One thousand good things in nature: Aspects of nearby nature associated with improved connection to nature. Environmental Values, 24(5), 603-619.

Richardson, M., Hunt, A., Hinds, J., Bragg, R., Fido, D., Petronzi, D., ... \& White, M. (2019). A Measure of Nature Connectedness for Children and Adults: Validation, Performance, and Insights. Sustainability, 11(12), 3250.

Richardson, M., McEwan, K., \& Garip, G. (2018). 30 Days Wild: who benefits most? Journal of Public Mental Health, 17(3), 95-104. 
Richardson, M., \& Sheffield, D. (2017). Three good things in nature: noticing nearby nature brings sustained increases in connection with nature. Psyecology, 8(1), 1-32.

Rout, U. (1999). Gender differences in stress, satisfaction and mental wellbeing among general practitioners in England. Psychology, Health \& Medicine, 4(4), 345-354.

Scannell, L., \& Gifford, R. (2013). Personally relevant climate change: The role of place attachment and local versus global message framing in engagement. Environment and Behavior, 45(1), 60-85.

Schultz, P. W. (2001). The structure of environmental concern: Concern for self, other people, and the biosphere. Journal of Environmental Psychology, 21(4), 327-339.

Shanahan, D. F., Bush, R., Gaston, K. J., Lin, B. B., Dean, J., Barber, E., \& Fuller, R. A. (2016). Health benefits from nature experiences depend on dose. Scientific Reports, 6, 28551.

Soga, M., \& Gaston, K. J. (2016). Extinction of experience: the loss of human-nature interactions. Frontiers in Ecology and the Environment, 14(2), 94-101.

Soga, M., Gaston, K. J., \& Yamaura, Y. (2017). Gardening is beneficial for health: A metaanalysis. Preventive Medicine Reports, 5, 92-99. 
Steg, L., \& Vlek, C. (2009). Encouraging pro-environmental behaviour: An integrative review and research agenda. Journal of Environmental Psychology, 29(3), 309-317.

Stern, P. (2000). Toward a coherent theory of environmentally significant behavior, Journal of Social Issues, 56, 407-424.

Tam, K. P. (2013). Concepts and measures related to connection to nature: Similarities and differences. Journal of Environmental Psychology, 34, 64-78.

Tanja-Dijkstra, K., Pahl, S., White, M.P., Andrade, J., May, J., Stone, R.S., Bruce, M., Mills, I., Auvrey, M., Gabe, R. \& Moles, D.R. (2018). The soothing sea: A virtual walk on the coast reduces experienced and recollected pain. Environment \& Behavior, 50, $599-625$

Truelove, H. B., Carrico, A. R., Weber, E. U., Raimi, K. T., \& Vandenbergh, M. P. (2014). Positive and negative spillover of pro-environmental behavior: An integrative review and theoretical framework. Global Environmental Change, 29, 127-138.

Twohig-Bennett, C., \& Jones, A. (2018). The health benefits of the great outdoors: A systematic review and meta-analysis of greenspace exposure and health outcomes. Environmental research, 166, 628-637

United Nations (2018). IPCC Climate Report 2018. Retrieved from: https://www.un.org/en/climatechange/reports.shtml 
van den Bosch, M., \& Sang, Å. O. (2017). Urban natural environments as nature-based solutions for improved public health-A systematic review of reviews. Environmental Research, 158, 373-384

Van Dillen, S. M., de Vries, S., Groenewegen, P. P., \& Spreeuwenberg, P. (2012). Greenspace in urban neighbourhoods and residents' health: adding quality to quantity. Journal of Epidemiology and Community Health, 66(6), e8-e8.

Watts, N., Adger, W. N., Agnolucci, P., Blackstock, J., Byass, P., Cai, W., ... \& Cox, P. M. (2015). Health and climate change: policy responses to protect public health. The Lancet, 386(10006), 1861-1914.

Weinstein, N., Balmford, A., Dehaan, C. R., Gladwell, V., Bradbury, R. B., \& Amano,

T. (2015). Seeing community for the trees: The links among contact with natural environments, community cohesion, and crime. BioScience, 65(12), 1141-1153.

Wheeler, B. W., Lovell, R., Higgins, S. L., White, M. P., Alcock, I., Osborne, N. J., ... \& Depledge, M. H. (2015). Beyond greenspace: an ecological study of population general health and indicators of natural environment type and quality. International journal of health geographics, 14(1), 17.

White, M. P., Yeo, N. L., Vassiljev, P., Lundstedt, R., Wallergård, M., Albin, M., \& Lõhmus, M. (2018). A prescription for "nature"-the potential of using virtual nature in therapeutics. Neuropsychiatric disease and treatment, 14, 3001. 
White, M.P., Pahl, S., Wheeler, B.W., Depledge, M.H. \& Fleming, L.E. (2017).

Natural environments and subjective wellbeing: Different types of exposure are associated with different aspects of well-being. Health \& Place, 45. 77-84.

White, M.P., Elliott, L.R., Wheeler, B.W. \& Fleming, L.E.F (2018). Neighbourhood greenspace is related to physical activity, but only among dog owners. Landscape \& Urban Planning, 174, 18-23.

White, M. P., Alcock, I., Grellier, J., Wheeler, B. W., Hartig, T., Warber, S. L., ... \& Fleming, L. E. (2019). Spending at least 120 minutes a week in nature is associated with good health and wellbeing. Scientific reports, 9(1), 7730.

Whitmee, S., Haines, A., Beyrer, C., Boltz, F., Capon, A. G., de Souza Dias, B. F., ... \& Horton, R. (2015). Safeguarding human health in the Anthropocene epoch: report of The Rockefeller Foundation-Lancet Commission on planetary health. The Lancet, 386(10007), 1973-2028.

Whitburn, J., Linklater, W., \& Abrahamse, W. (2019). Meta-analysis of human connection to nature and proenvironmental behavior. Conservation Biology.

Whitburn, J., Linklater, W. L., \& Milfont, T. L. (2018). Exposure to urban nature and tree planting are related to pro-environmental behavior via connection to nature, the use of nature for psychological restoration, and environmental attitudes. Environment and Behavior, 0013916517751009. 
World Health Organisation (2013). Health and the environment in the who European region. Retrieved from: http://www.euro.who.int/ data/assets/

World Health Organisation. (2015). Health in 2015: from MDGs to SDGs. Retrieved from: www.who.int/gho/publications

Wyles, K., White, M.P., Hattam, C., Pahl, S. \& Austin, M. (2019). Nature connectedness and well-being from recent nature visits: The role of environment type and quality. Environment \& Behaviour. 51(2), 111-143.

Zelenski, J. M., Dopko, R. L., \& Capaldi, C. A. (2015). Cooperation is in our nature: Nature exposure may promote cooperative and environmentally sustainable behaviour. Journal of Environmental Psychology, 42, 24-31.

Zylstra, M. J., Knight, A. T., Esler, K. J., \& Le Grange, L. L. (2014). Connectedness as a core conservation concern: An interdisciplinary review of theory and a call for practice. Springer Science Reviews, 2(1-2), 119-14 
